\title{
Benefícios do bem-estar animal na produtividade e na sanidade de ovinos
}

Benefits of animal welfare in productivity and health sheep

Beneficios de bienestar animal en la productividad y ovejas la salud

Diego Marostica Lino

Mestrando em Ciência e Tecnologia Animal, UNESP - FEIS/SP, Brasil. dmarostical@hotmail.com

\author{
Rafael Silvio Bonilha Pinheiro \\ Professor Doutor, UNESP - FEIS/SP, Brasil. \\ rafaelsbp@bio.feis.unesp.br
}

\section{Vanessa Veronese Ortunho} Professora substituta, UNESP - FEIS/SP, Brasil. vanessaverort@yahoo.com.br 


\section{RESUMO}

Debates sobre a preservação do meio ambiente e criações de animais produzidos com bem-estar animal vem ganhando muito destaque nos últimos anos. A ovinocultura para atender as exigências do mercado atual tem feito investimentos nos sistemas de produção no manejo racional dos ovinos, sem esquecer os princípios básicos de sanidade e nutrição animais. Essa revisão tem como objetivo reunir informações de pesquisas científicas e trabalhos técnicos que tem comentado sobre os benefícios do bem-estar animal na produtividade e na sanidade de ovinos.

PALAVRAS CHAVES: Ovinocultura. Produção animal. Saúde animal.

\section{ABSTRACT}

Debates on the preservation of the environment and animal creations produced with animal welfare is gaining much prominence in recent years. The sheep industry to meet the demands of the current market has made investments in production systems in the rational management of sheep, without forgetting the basic principles of health and nutrition animals. This review aims to gather scientific research information and technical work that has commented on the benefits of animal welfare in productivity and health of sheep.

KEYWORDS: Animal health. Animal production. Sheep industry.

\section{RESUMEN}

Los debates sobre la conservación de las creaciones de medio ambiente y de los animales producidos con el bienestar animal está ganando mucho protagonismo en los últimos años. La industria de las ovejas para satisfacer las exigencias del mercado actual ha hecho inversiones en los sistemas de producción en la gestión racional de ovejas, sin olvidar los principios básicos de los animales de salud y nutrición. Esta revisión tiene como objetivo recoger información investigación científica y el trabajo técnico que se ha comentado sobre los beneficios de bienestar animal en la productividad y la salud de las ovejas.

PALABRAS CLAVE: Ganado. Oveja. Salud de los animales. 


\section{Introdução}

O Brasil ocupa o 18 maior rebanho de ovinos do mundo, com mais de 14 milhões de animais, distribuído em 436 mil estabelecimentos agropecuários. A maioria destes ovinos é destinada a produção de carne, cuja participação socioeconômica é crescente e vem se firmando como uma alternativa de retorno econômico para o produtor rural (FAO, 2015).

O mercado consumidor vem exigindo que as atividades de produção animal, inclusive a criação de ovinos, respeitem as questões ambientais e de bem-estar animal e para isso, é fundamental a introdução do manejo racional, tendo impacto na qualidade de vida dos animais e na qualidade do produto final (FAWC, 2011). Para atender essa exigência do mercado não se pode esquecer dos princípios básicos de maximização da genética, da alimentação e da sanidade de um rebanho (BARROS; CAVALCANTE; VIEIRA, 2005).

Produzir a quantidade de alimento suficiente para uma população estimada em 9 bilhões de pessoas em 2050, e ao mesmo tempo preservar a natureza são os grandes desafios da agricultura e da pecuária mundial deste século. Na avaliação de representantes do agronegócio brasileiro, é importante que estes setores transformem as questões ambientais em uma agenda positiva em favor de uma produção mais eficiente, de maior qualidade e capaz de limitar a expansão das fronteiras agrícolas Com os novos tempos, os pecuaristas devem encarar como oportunidades de negócios, a recuperação de áreas de proteção ambiental e os investimentos na diversificação de suas propriedades (ORTUNHO, 2013). O Brasil, que há décadas assumiu a condição de celeiro do mundo, tem um papel importante nesse novo cenário da agropecuária mundial, que será pautado pelo aumento da demanda por alimentos e pelas restrições ambientais à abertura de novas áreas agrícolas (SOUZA, 2011).

Neste cenário, a ovinocultura de corte está se tornando uma atividade cada vez mais atraente para a diversificação da produção agropecuária, pelos ovinos serem animais dóceis, de fácil lida e que não necessitam de áreas extensas para a criação, quando comparados com os bovinos, por apresentarem período de gestação mais curto em relação às vacas, pela idade de abate ser menor nos cordeiros em relação aos bois, permitindo que os rebanhos ovinos apresentem altas taxas de desfrute e uma elevada produção de carne por hectare ano. Ainda há o fato de que a espécie ovina apresenta um rápido ciclo reprodutivo, sendo que as borregas e os machos atingem a puberdade entre o sexto e oitavo mês de vida (VECHI, 2010).

No entanto, os ovinos são suscetíveis a uma série de doenças, algumas delas características da própria espécie, que se não bem controladas através de um adequado manejo sanitário, afetam a eficiência reprodutiva do rebanho, prejudicam o desenvolvimento dos animais e provocam altos índices de mortalidade. As endoparasitoses, quando não bem controladas, causam perda de peso de 30 a 40\% nos animais jovens, grande mortalidade de cordeiros, além do gasto com medicamentos, tornando a ovinocultura uma atividade economicamente inviável e impraticável pelos produtores rurais (VECHI, 2010).

Para que a criação de ovinos dê bons resultados é preciso obter alta eficiência reprodutiva do rebanho e alto índice de desmama, o que implica em maior número de cordeiros nascidos e baixa taxa de mortalidade na fase de amamentação. Estes fatos, aliados a um bom desempenho corporal dos cordeiros e a custos de produção compatíveis com o mercado da 
carne, garantiriam a boa oferta de animais na idade ideal para o abate a preços competitivos (VECHI, 2010).

A evolução da ovinocultura brasileira torna-se cada vez mais evidente, a superação anual dos números é notória, mantendo o setor aquecido, em constante crescimento e com uma tendência altamente positiva em longo prazo, permitindo a consolidação e o desenvolvimento da ovinocultura comercial em todo o país, aumentando o número de produtores desses animais e de investimento nessa cultura (SOUZA, 2010).

À medida que foram incluídos o melhoramento genético e a seleção nos programas de criação de ovinos, estes animais passaram a apresentar maior ritmo de crescimento, maior ganho de peso, melhor conversão alimentar e maior rendimento de carcaça, consequentemente as suas necessidades nutricionais tornaram-se mais elevadas e se caso não forem atendidas aumentase a probabilidade do aparecimento de diversas patologias (MEDINA; NATEL, 2010).

É indispensável a participação e o comprometimento de todos os agentes envolvidos na cadeia da ovinocultura como governo, pesquisadores, técnicos, produtores, associações, indústrias processadoras e comerciantes para o crescimento da atividade, para o estabelecimento de diretrizes, cumprimento de metas e articulação entre todos os elos da cadeia produtiva, para que a atividade desenvolva e atenda todas as exigências de mercado (HOLANDA JUNIOR; SÁ; ARAúJO, 2010).

\section{Objetivos}

O presente artigo de revisão tem como objetivo reunir informações da literatura em relação ao bem-estar, produtividade e sanidade na ovinocultura.

\section{Metodologia}

O termo "bem-estar animal" é muito amplo, pois inclui uma somatória de elementos que contribuem para a qualidade de vida do animal, levando a um estado de harmonia e equilíbrio com o ambiente em que se encontra, caracterizado por suas condições físicas e sanitárias adequadas. Assim, o animal que se encontra em bem-estar entende-se que está saudável, confortável, bem alimentado, seguro, hábil para expressar seu comportamento normal. Portanto, bem-estar animal requer prevenção de doença, tratamento veterinário, manejo nutricional e instalações adequadas (BRASIL, 2008).

Por muito tempo o bem-estar dos animais e a alta produtividade eram considerados antagônicos, porém muitos estudos têm demonstrado que o estresse excessivo e o sofrimento dos animais têm efeito negativo na produtividade e na qualidade dos alimentos. Quando não há bem-estar, pode ocorrer queda na produção, na reprodução e no crescimento, aumento da incidência de doenças e produção de carne, leite e lã de qualidade inferior na ovinocultura.

O bem-estar animal, seja na criação, nas atividades de manejo, no transporte, na comercialização ou mesmo no local de abate, deve ter direito às denominadas 5 liberdades que Ihes garantam uma vida sem sofrimentos desnecessários. Estes conceitos definem padrões do que é aceitável em termos de respeito ao bem-estar (FAWC, 2011). Estas 5 Liberdades são: 
1) Ausência de fome e sede: através do acesso a água e a uma dieta que mantenha a saúde e o vigor dos animais;

2) Livres de dor, ferimentos ou doenças: através da prevenção, do diagnóstico precoce e tratamento rápido, devem ser evitados dor e sofrimentos desnecessários aos animais;

3) Ausência de desconforto: através de um ambiente apropriado, incluindo abrigo e uma área de descanso confortável;

4) Liberdade de expressar comportamento normal: proporcionando espaço suficiente, instalações apropriadas e companhia de animais da mesma espécie;

5) Ausência de medo ou sofrimento: assegurando condições para existirem alojamentos, manejo e pessoal devidamente qualificado de forma a evitar medos e sofrimentos desnecessários.

No Brasil, a Instrução Normativa no56 (IN56) de 06 de novembro de 2008, estabeleceu as "Recomendações de boas práticas de bem-estar para animais de produção e de interesse econômico - REBEM" (BRASIL, 2008), o que segundo a normativa, devem ser observados os princípios para garantia do bem-estar animal como:

a) Proceder ao manejo cuidadoso e responsável nas várias etapas da vida do animal, desde o nascimento, criação e transporte;

b) Possuir conhecimentos básicos de comportamento animal a fim de proceder ao adequado manejo;

c) Proporcionar dieta satisfatória apropriada e segura, adequada as diferentes fases de vida do animal;

d) Assegurar que as instalações sejam projetadas apropriadamente aos sistemas de produção das diferentes espécies, de forma a garantir a proteção, descanso e bem-estar animal;

e) Manejar e transportar os animais de forma adequada para reduzir o estresse e evitar contusões e o sofrimento desnecessários;

f) Manter o ambiente de criação em condições higiênicas.

Segundo Molento (2005), pode-se inferir que atender o bem-estar animal agrega um valor econômico ao produto e ao inserir-se no mundo da economia, o bem-estar animal passou a ser parte integrante dos cálculos do valor econômico dos produtos.

McInerney (2004) ressalta que o bem-estar animal pode assumir um valor econômico independente do valor puramente produtivo dos animais, e que esta visão é essencial para justificar que se tomem atitudes racionais para assegurar melhorias na qualidade de vida destes animais, que envolvem o emprego de recursos e incrementos nos custos de produção. O bem-estar, objetivamente, segundo Roll, Rech e Xavier (2006), não pode ser avaliado de uma única forma, mas, sim, por meio de um enfoque multidisciplinar, que combine uma série de medições complementares. Entre elas: perfil fisiológico e bioquímico; indicadores de comportamento; estado sanitário; condições físicas e higiênicas dos animais; além de índices produtivos.

Quanto ao perfil fisiológico e bioquímico, estudos científicos têm sido realizados e Andrade, Souza e Pereira Filho (2007), ao trabalharem com ovinos da raça Santa Inês, com peso vivo médio de $21,5 \mathrm{~kg}$ e 120 dias idade, distribuídos em três ambientes: sem sombra; sombra natural, proveniente de uma árvore; sombra artificial, constituída por uma tela de polietileno 
com $80 \%$ de retenção (sombrite), e níveis crescentes de suplementação concentrada (0, 1,0 e $1,5 \%$ do peso vivo), concluíram que a sombra natural ou artificial auxiliou os ovinos a manterem a homeotermia com menor esforço do aparelho termorregulatório.

Pereira et al. (2008) verificaram redução significativa no ganho de peso de animais sem acesso a sombra em relação aos que tiveram acesso a sombra. Assim como os ovinos da raça Santa Inês que foram avaliados por Neiva et al. (2004) que foram mantidos em um ambiente de sombra e sol, e os autores observaram que o consumo de matéria seca foi maior no grupo de animais mantidos a sombra, os quais apresentaram maior ganho de peso $(174 \mathrm{~g} / \mathrm{dia}) \mathrm{em}$ relação aos animais que recebiam radiação solar direta (122g/dia).

Segundo Ferreira (2005), quando os animais são mantidos em estresse por calor, seu organismo utiliza-se de mecanismos para diminuição da produção de calor proveniente da fermentação ruminal porque, quanto mais calor ele produz (calor endógeno), maior será o esforço para dissipação do calor excedente para o ambiente. Assim, o primeiro mecanismo a ser utilizado é a redução do consumo de alimentos. Esse comportamento é adotado para se diminuir a termogênese induzida pela dieta.

O bem-estar dos animais durante o transporte deve ser avaliado através do comportamento, de parâmetros fisiológicos e de medidas de qualidade de carcaça. Além disso, deve-se salientar que um transporte adequado deve priorizar a manutenção da saúde dos animais, evitando lesões, doenças ou até mesmo a morte dos mesmos.

Segundo Sartorelli et al. (2003), os animais de produção estão sempre expostos a fatores estressantes, que afetam o bem-estar, a reprodução, a produtividade, a sanidade, baseado nisso, os autores estudaram ovelhas Charolle, não lactantes e não prenhes, as quais foram submetidas aos seguintes tratamentos: isoladas do rebanho por 1 hora e em seguida transportadas por 2 horas num caminhão, os animais do grupo controle foram submetidas ao estresse induzido com injeções de ACTH. As análises bioquímicas revelaram que o estresse natural e o induzido aumentaram o valor de cortisol, porém somente o estresse natural provocou um aumento na glicemia, de ácidos graxos não esterificados e aumento na concentração de $\beta$ - hidroxibutirato.

Erros de manejo que prejudicam o bem-estar dos animais incluem uma nutrição inadequada, falta de limpeza, desinfecção e higiene do local de produção, instalações mal planejadas, pessoas não treinadas para atividade e erros de manejo com os animais. Tais falhas, geralmente são consequências da total falta de elaboração de um planejamento ou de um programa de manejo sanitário, nutricional e que inclua a relação de bem-estar na atividade de ovinocultura (PINHEIRO; BRITO, 2009).

A nutrição adequada é imprescindível para o ovinocultor que deseja atingir boa produtividade e rentabilidade na sua criação. $O$ grande desafio dos produtores é gerenciar a alimentação do rebanho de forma correta, para que este não seja um fator limitante na produção (VIANA, 2001).

Macedo e Macedo (2008) observaram que a nutrição inadequada da ovelha prenhe, apresentou alta correlação com mortalidade do cordeiro recém-nascido, pois influenciou de forma significativa o peso ao nascer e a maior ou menor susceptibilidade a doenças e adversidades climáticas. 
A organização do sistema de produção, em uma perspectiva empresarial, permite não somente a escrituração zootécnica do rebanho, mas também o registro e monitoramento de um conjunto de medidas de manejo de maneira integrada, buscando o controle do manejo da produção e saúde do rebanho de forma preventiva. A sanidade abrange uma série de atividades técnicas, conduzidas para manter as condições de saúde dos animais, as quais são influenciadas pelas práticas de manejo, meio ambiente, genótipo e entre outras. O simples sinal clínico de doenças, em um animal ou rebanho, é indicativo de perdas econômicas sérias e palpáveis ao bolso do produtor, entretanto as maiores perdas de produtividade são aquelas invisíveis, resultantes do desequilíbrio da interação entre os agentes biológicos, hospedeiros e ao meio ambiente (ALVES; PINHEIRO, 2005).

O planejamento é o princípio básico para o manejo sanitário da ovinocultura, devendo ser implantado em propriedades como forma de organizar os procedimentos adotados na produção de ovinos. Principalmente para prevenir a ocorrência de enfermidades, as quais o rebanho esteja susceptível. A implantação, condução e monitoramento desta gestão sanitária requerem profissionais especializados e que conheçam todos os pontos problemáticos do sistema produtivo. O ideal é que este planejamento seja elaborado para prevenir situações que causem comprometimento do bom estado sanitário de uma propriedade. Porém, o que ocorre com maiores frequências é a requisição de tal serviço quando um problema já se encontra instalado e, em alguns casos, com alguma enfermidade já acometendo parte ou até mesmo todo o rebanho (PINHEIRO; BRITO, 2009).

É necessário observar preliminarmente os tipos de manejo sanitário, reprodutivos e nutricionais a que os animais são submetidos. E de posse de todos esses elementos e após as devidas análises e interpretações, será possível então a elaboração da ferramenta fundamental da gestão sanitária estratégica (o calendário sanitário). Essa é a melhor maneira de se aperfeiçoar os procedimentos relacionados aos manejos sanitário, zootécnico e reprodutivo do rebanho em suas diferentes categorias animais, onde o planejamento das ações e programação das atividades ao longo de todo o "ano zootécnico" pode ser apresentado e distribuído em semanas e ou quinzenas.

\section{Conclusão}

Desde os primórdios da civilização, os ovinos têm tido grande significado na vida do ser humano, sendo então a ovinocultura uma das mais antigas atividades do homem. Atualmente, a ovinocultura é uma atividade econômica presente em quase todos os continentes, sendo muito importante em alguns países como Austrália, Nova Zelândia e Grã-Bretanha.

No Brasil, a ovinocultura tem se tornado uma atividade viável para os pecuaristas, porque a demanda pela carne ovina tem aumentado no mercado interno, tendo então atraído novos produtores, porém para que haja sucesso são necessários investimentos para atender as exigências mercadológicas: como a produção de animais em sistema sustentável, seguindo as recomendações de criação com bem-estar, atender os princípios de sanidade e a necessidade de uma boa nutrição representam regras para uma criação que vise à alta produtividade com animais sadios. 


\section{REFERÊNCIAS BIBLIOGRÁFICAS}

ALVES, F.S.F.; PINHEIRO, R.R. Manejo sanitário de caprinos e ovinos. EMBRAPA-CNPC, Comunicado Técnico, v.9, 2005. $11 \mathrm{p}$.

ANDRADE, I.S.; SOUZA, B.B.; PEREIRA FILHO, J.M. Parâmetros fisiológicos e desempenho de ovinos Santa Inês submetidos a diferentes tipos de sombreamento e a suplementação em pastejo. Ciência e Agrotecnologia, v.31, n.2, p.540-547, 2007.

BARROS, N.N.; CAVALCANTE, A.C.R.; VIEIRA, L. S. Boas práticas na produção de caprinos e ovinos de corte. Série Documentos / EMBRAPA Caprinos, Sobral. v.57, 2005. 40 p.

BRASIL - Ministério da Agricultura, Pecuária e Abastecimento, MAPA - INSTRUÇãO NORMATIVA № 56 (IN56) "Recomendações de Boas Práticas de Bem-Estar para Animais de Produção e de Interesse Econômico - REBEM", Novembro 2008, Disponível em: <

http://www.agricultura.gov.br/arq_editor/file/Desenvolvimento_Sustentavel/Producao-Integrada-

Pecuaria/IN\%2056\%20de\%202008.pdf>. Acessado em: 25 fev. 2014.

FAO - Organização das Nações Unidas para a Agricultura e Alimentação. Elaboração da Unidade de Avaliações Econômicas e de Mercado - INDI. Ano 2015. Disponível em: <www.faostat.fao.org>. Acessado em: 04 abr. 2016.

FAWC - Farm Animal Welfare Council - Final Report. Março 2011. Disponível em: < http://www.fawc.org.uk/pdf/fawc-final-report-2011-110324.pdf>. Acessado em: 07 jun. 2014.

FERREIRA, R. A. Maior produção com melhor ambiente para aves, suínos e bovinos. Viçosa, MG: Aprenda Fácil, 2005, $371 \mathrm{p}$.

HOLANDA JUNIOR, E.V.; SÁ, J. L.; ARAÚJO, G.G.L. Articulação dos segmentos da cadeia produtiva de caprinos e ovinos os fluxos alternativos de comercialização. In: SIMPÓSIO INTERNACIONAL SOBRE CAPRINOS E OVINOS DE CORTE, 2.; SIMPÓSIO INTERNACIONAL SOBRE AGRONEGÓCIO DA CAPRINOCULTURA LEITEIRA, 1., 2010, João Pessoa. Anais... João Pessoa : EMEPA-PB, 2010. Disponível em: <http://www.infoteca.cnptia.embrapa.br/bitstream/CPATSA/27430/1/OPB988.pdf>._Acesso em: 2 jun. 2015.

MACEDO, V. P.; MACEDO, L. G. Principais causas de mortalidade de cordeiros: uma revisão. PUBVET, v.2, n.16, 2008. Disponível em: <http://pubvet.com.br/material/Macedo205.pdf>. Acesso em: 14 jun. 2015.

MCINERNEY, J. P. Animal welfare, economics and policy - report on a study undertaken for the Farm \& Animal Health Economics Division of Defra, February 2004. Disponível em:

<http://www.defra.gov.uk/esg/reports/animalwelfare.pdf>. Acesso em: 01 jun. 2014.

MEDINA, I. M.; NATEL, S. A. O uso de suplementação para diferentes categorias. Piracicaba: MilkPoint, 2010. Disponível em: <http://www.farmpoint.com.br/o-uso-de-suplementacao-para-diferentescategorias_noticia_54299_3_28_.aspx>. Acesso em: 24 abr. 2015. MOLENTO, C.F.M. Bem-Estar e produção animal: aspetos econômicos - Revisão. Archives of Veterinary Science. v.10, n.1, p.1-11, 2005.

NEIVA, J.N.M. et al. Efeito do estresse climático sobre os parâmetros produtivos e fisiológicos de ovinos Santa Inês mantidos em confinamento na região litorânea do Nordeste do Brasil. Revista Brasileira de Zootecnia, v.33, n.3, p.668-678, 2004.

ORTUNHO, V.V. Revisão da literatura: mineralização e perfil metabólico em ovinos. PUBVET, v. 7, n. 10, Ed. 233, Art. 1537, 2013.

PEREIRA, R.G.A. et al. A sombra faz bem para os ovinos no trópico úmido. Revista O Berro, n. 110, p. 116-120, 2008.

PINHEIRO, A.A.; BRITO, I.F. Bem-Estar e Produção Animal. Série Documentos / EMBRAPA Caprinos. v.93, 2009. 25 p. 
ROLL, V.F.; RECH, C.L.S.; XAVIER, E.G. Comportamento animal: Conceitos e técnicas de estudo. Universidade Federal de Pelotas/Editora Universitária, p.85-103, 2006.

SARTORELLI, P. et al. The effect of natural and pharmacological stressors on sheep: haematological, biochemical and granulocytic functional changes. Veterinary Research Communications, v. 27, suppl. 1, p.723-726, 2003.

SOUZA, D. A. Carne ovina importada: volume, valores e perfil. Piracicaba: FarmPoint, 2010. Disponível em: $<$ http://www.farmpoint.com.br/carne-ovina-importada-volume-valores-e-perfil_noticia_62396_1_2_.aspx>. Acesso em: 28 mai. 2010.

SOUZA, E. 10 práticas sustentáveis. Globo Rural, n.312, p. 36-37, 2011.

VECHI, J.B. A Criação de ovinos em Mato Grosso: uma alternativa para o ingresso de pequenos e médios produtores rurais na atividade. Cuiabá: Sedraf, 2010. Disponível em:

<http://www.seder.mt.gov.br/arquivos/A_c8e35ceb0ca8142aaaff2f55be2c4114CRIACAO_OVINOS_PROPOSTA_3. doc>. Acesso em: 28 abr. 2010.

VIANA, D.F. Alguns aspectos da toxemia da prenhez em pequenos ruminantes. 2001. 64 f. Monografia (Graduação em Medicina Veterinária). Escola de Medicina Veterinária - Universidade Estadual da Bahia, Salvador, BA, 2001. 